\title{
Connexin40 nonsense mutation in familial atrial fibrillation
}

\author{
YI-QING YANG ${ }^{1}$, XIAN-LING ZHANG ${ }^{2}$, XIN-HUA WANG ${ }^{2}$, HONG-WEI TAN $^{2}$, \\ HAI-FENG SHI ${ }^{2}$, WEI-FENG JIANG ${ }^{2}$, WEI-YI FANG ${ }^{2}$ and $\mathrm{XU} \mathrm{LIU}^{2}$
}

Departments of ${ }^{1}$ Cardiovascular Research, and ${ }^{2}$ Cardiology, Shanghai Chest Hospital Affiliated
to Shanghai Jiaotong University, 241 West Huaihai Road, Shanghai 200030, P.R. China

Received May 11,2010; Accepted July 12, 2010

DOI: 10.3892/ijmm_00000505

\begin{abstract}
Atrial fibrillation (AF) is the most common sustained cardiac arrhythmia associated with substantial morbidity and mortality. Genetic variants play important roles in the pathogenesis of AF. However, AF is a genetically heterogeneous disorder, and the genetic determinants in most patients with AF remain to be identified. In this study, the entire coding region of the connexin 40 gene, encoding the cardiac gap junction membrane channel protein $\alpha 5$, was sequenced in 126 unrelated probands with familial AF. A novel heterozygous mutation, c.145C $>\mathrm{T}$, in connexin 40 , was identified in a proband. The mutation was predicted to introduce a premature stop codon at amino acid position 49 (p.Q49X). This nonsense mutation was present in all the living relatives of the mutation carrier, co-segregating with $\mathrm{AF}$ in the family with a penetrance of $100 \%$. However, it was absent in 200 ethnically matched unrelated control individuals. The findings suggest a pathogenic link between the compromised connexin40 function and familial AF, hence providing new insight into the molecular mechanisms involved in $\mathrm{AF}$.
\end{abstract}

\section{Introduction}

Atrial fibrillation (AF) is the most common form of cardiac arrhythmia encountered in clinical practice and an important contributor to increased mortality and significant morbidity. The occurrence of AF increases dramatically with age, with a prevalence rising from $\sim 0.1 \%$ among adults $<55$ years of age, to nearly $10 \%$ in subjects $>80$ years old (1). Men and women $\geq 40$ years of age, have a $\sim 25 \%$ risk for the development of AF (2). Compared to individuals with sinus rhythm, patients

Correspondence to: Dr Yi-Qing Yang, Department of Cardiovasular Research, or Dr Xu Liu, Department of Cardiology, Shanghai Chest Hospital Affiliated to Shanghai Jiaotong University, 241 West Huaihai Road, Shanghai 200030, P.R. China

E-mail: yang99yang66@hotmail.com

E-mail: xkliuxu@hotmail.com

Key words: atrial fibrillation, gap junction channel, genetics with AF have a 6-fold increased risk of stroke and a 2-fold increased risk of death (3). While the structural heart diseases or systemic disorders, such as coronary artery disease, rheumatic heart disease, cardiomyopathy, congenital heart defects, pericarditis, congestive heart failure, hypertension, hyperthyroidism, and electrolyte imbalance, predispose to AF (4), $\mathrm{AF}$ also occurs in individuals without any known risk factors and growing evidence points to a genetic basis for the pathogenesis of AF (5-13). Furthermore, several chromosomal loci linked to AF have been mapped and AF-related mutations in multiple genes, including the connexin 40 encoding cardiac gap junction membrane channel protein $\alpha 5$, have been identified (14-26). However, AF is a genetically heterogeneous disorder and the molecular basis of AF remains unknown in the majority of cases (27).

Gap junctions are intercellular channels responsible for the exchange of ions and small molecules between adjacent cells. These channels mediate the electrical coupling of mammalian cardiomyocytes, and this is essential for the fast and coordinated cardiac action potential propagation. The functional gap junction channel is composed of 2 hemichannels, also known as connexons, and 1 is provided by each cell. Connexons are the hexamers of the membranespanning proteins called connexins. At present, $>20$ connexin genes have been identified in mice and humans (28). In the human heart, myocyte gap junctions are constructed mainly by 3 different connexin isoforms, connexin40, connexin 43 , and connexin45. Connexin40 is expressed selectively in the atrial myocytes, the atrioventricular node, the His-bundle and the ventricular conduction system (Purkinje fibers), predominantly contributing to the electrical synchronization of the atrium and the rapid conduction of impulses in the HisPurkinje (29). In connexin40-deficient mice, spontaneous or inducible dysrhythmias as well as conduction abnormalities, have been observed (30). In goats, alterations in the expression levels and distribution patterns of atrial connexin40, could constitute a cellular substrate underlying the susceptibility and perpetuation of AF (31). In humans, cardiac connexin40 remodeling could give rise to anomalous electrical coupling, thus forming an electrophysiological matrix with potential arrhythmogenic effects (32). By reducing connexin40 protein levels, 2 closely linked polymorphisms in the promoter region of the connexin 40 gene, have strongly been associated with enhanced atrial vulnerability and an increased risk of idiopathic AF (33-35). Additionally, the loss-of-function missense mutations of connexin 40 have been identified in 
patients with sporadic AF (23). These findings rationalise the scanning of connexin 40 as a logical candidate gene for familial AF.

In this study, we analyzed the connexin40 gene in 126 unrelated index cases with familial AF and identified a nonsense heterozygous mutation in 1 case, including the family members. This novel mutation resulted in a truncated protein with only the initial 48 out of 358 amino acids, and was cosegregated with AF in the family with complete penetrance. To our knowledge, this is the first description of the relationship between a defect in connexin40 and susceptibility to familial AF, thereby expanding the spectrum of mutations in connexin40 which are linked to $\mathrm{AF}$, and thus providing new insight into the molecular mechanisms involved in AF.

\section{Materials and methods}

Study participants. A total of 126 unrelated kindreds with familial AF were identified among the Chinese population. The controls were 200 ethnically matched unrelated healthy individuals. Peripheral venous blood specimens were prepared and clinical data including medical records, an electrocardiogram (ECG) and echocardiography reports, were collected. The study participants were clinically classified using a consistently applied set of definitions $(27,36)$. Briefly, the diagnosis of AF was made by a standard 12-lead electrocardiogram demonstrating no $\mathrm{P}$-waves and irregular $\mathrm{R}-\mathrm{R}$ intervals, regardless of clinical symptoms. Lone AF was defined as AF occurring in individuals $<60$ years of age without other cardiac or systemic diseases found by physical examination, electrocardiogram, transthoracic echocardiogram, and extensive laboratory tests. Familial AF was defined as the presence of lone AF in $\geq 1$ first-degree relatives of the proband. Relatives with AF occurring at any age in the setting of structural heart disease (hypertensive, ischemic, myocardial or valvular) were classified as 'undetermined' for having an inherited form of AF. The 'undetermined' classification was also used if the documentation of AF on an electrocardiogram tracing was lacking in the relatives with symptoms consistent with AF (palpitations, dyspnea and light-headedness), or if a screening electrocardiogram and echocardiogram were not performed, regardless of the symptoms. Relatives were classified as 'unaffected' if they were $\geq 18$ years of age, asymptomatic and had a normal electrocardiogram. In addition, paroxysmal AF was defined as AF lasting $>30 \mathrm{sec}$, terminating spontaneously. Persistent $\mathrm{AF}$ was defined as $\mathrm{AF}$ lasting $>7$ days and requiring either pharmacological therapy or electrical cardioversion for termination. AF that was refractory to cardioversion or that was allowed to continue, was classified as permanent (37). The study protocol was reviewed and approved by the local institutional ethics committee and written informed consent was obtained from all the participants prior to the study.

Genetic studies. Genomic DNA from all the participants was extracted from blood lymphocytes with the Wizard Genomic DNA Purification Kit (Promega). The candidate gene, connexin40, was screened in 126 unrelated probands with familial AF and connexin40 genotyping in the relatives of a mutation carrier and 200 ethnically matched unrelated healthy
Table I. Clinical characteristics of the 126 probands with familial AF.

\begin{tabular}{lcc}
\hline & Number & \% or range \\
\hline Male:female & $65: 61$ & $52: 48$ \\
Age of onset & 44.5 & $25-58$ \\
Paroxysmal AF on presentation & 92 & 73 \\
Progression to permanent AF & 20 & 22 \\
History of cardioversion & 23 & 18 \\
History of pacemaker & 8 & 6 \\
Resting heart rate (bpm) & 72.5 & $55-141$ \\
Systolic blood pressure (mm Hg) & 128.5 & $96-172$ \\
Diastolic blood pressure (mm Hg) & 79.1 & $65-108$ \\
Body mass index (kg/m $\left.{ }^{2}\right)$ & 22.6 & $20-24$ \\
Left atrial dimension (mm) & 36 & $27-40$ \\
Left ventricular ejection fraction & 0.6 & $0.53-0.68$ \\
Fasting blood glucose (mmol/L) & 4.6 & $3.9-5.8$ \\
Total cholesterol (mmol/L) & 3.9 & $3.4-4.9$ \\
Triglycerides (mmol/L) & 1.2 & $0.5-1.5$ \\
Medications & & \\
Aspirin & 41 & 33 \\
Warfarin & 22 & 17 \\
B-blocker & 38 & 30 \\
Calcium channel blocker & 19 & 15 \\
Digoxin & 43 & 34 \\
\hline
\end{tabular}

control individuals, was conducted subsequently for the presence of a mutation identified in a proband. The referential genomic DNA sequence of connexin40 was derived from GenBank (accession no. NG_009369). With the aid of on-line Primer3 software (http://frodo.wi.mit.edu), the primer pairs used to amplify the complete coding region of connexin 40 by polymerase chain reaction (PCR) were designed as follows: Primer 1 forward 5'- GCA, TCT, GTT, CCC, TGG, CTG, TGC -3', and backward 5'- CGG, ACC, TCT, TTG, GCC, CTC, TCG -3' (the PCR product was 404 base pairs in size); primer 2 forward 5'- CGC, CCT, CTC, TGG, TGT, ACA, TGG -3', and backward 5'- CCA, GAA, AGC, TGG, CAC, TTA, GCC -3' (the product was 496 base pairs); primer 3 forward 5'- CCT, GGG, CTG, GAA, GAA, GAT, CAG -3', and backward 5'- GCC, AAG, CAG, TGA, TGA, CAG, TG -3' (the product was 500 base pairs). PCR was carried out using HotStar Taq DNA Polymerase (Qiagen) on a PE 9700 Thermal Cycler (Applied Biosystems). The amplified products were purified with QIAquick Gel Extraction Kit (Qiagen). Both strands of each PCR product were sequenced with the BigDye ${ }^{\circledR}$ Terminator v3.1 Cycle Sequencing Kit (Applied Biosystems) under an ABI PRISM 3130 XL DNA Analyzer (Applied Biosystems). DNA sequences were viewed and analyzed with the DNA Sequencing Analysis Software v5.1 (Applied Biosystems). The variant was validated by re-sequencing an independent PCR-generated amplicon from the participant (done by the Shensu DNA Sequencing Facility) and met our quality control thresholds with a call rate of $>99 \%$. 


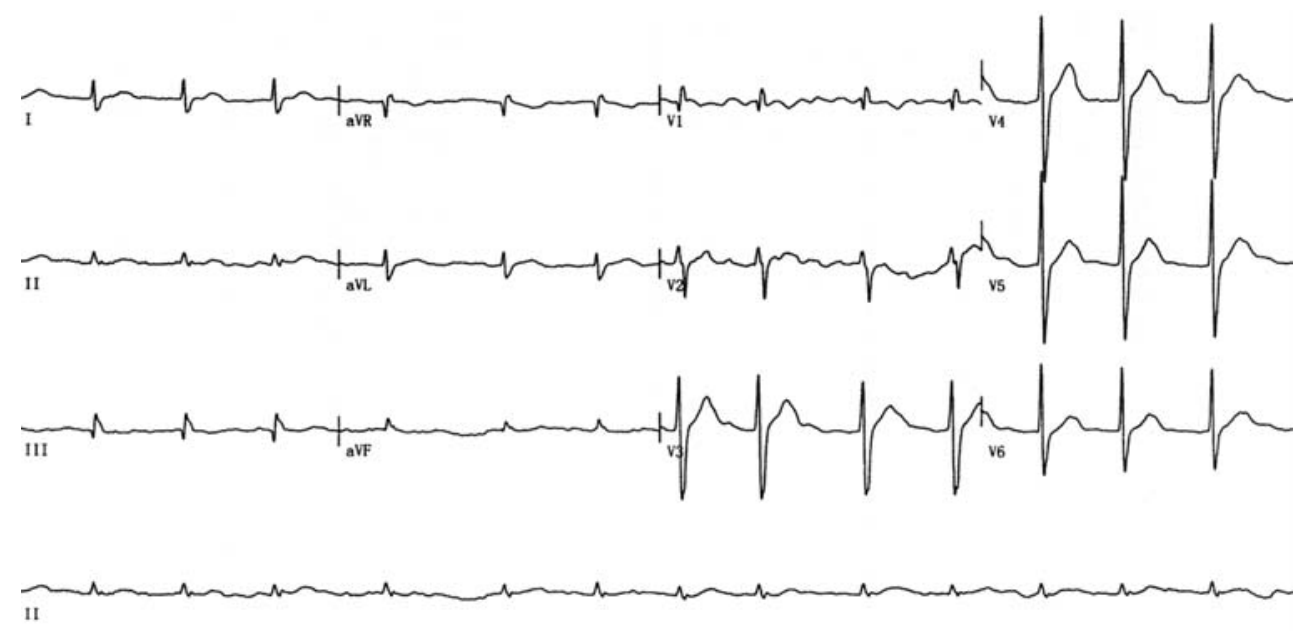

Figure 1. Standard 12-lead surface electrocardiogram of the proband (II-6). The electrocardiogram shows atrial fibrillation combined with incomplete right bundle branch block.

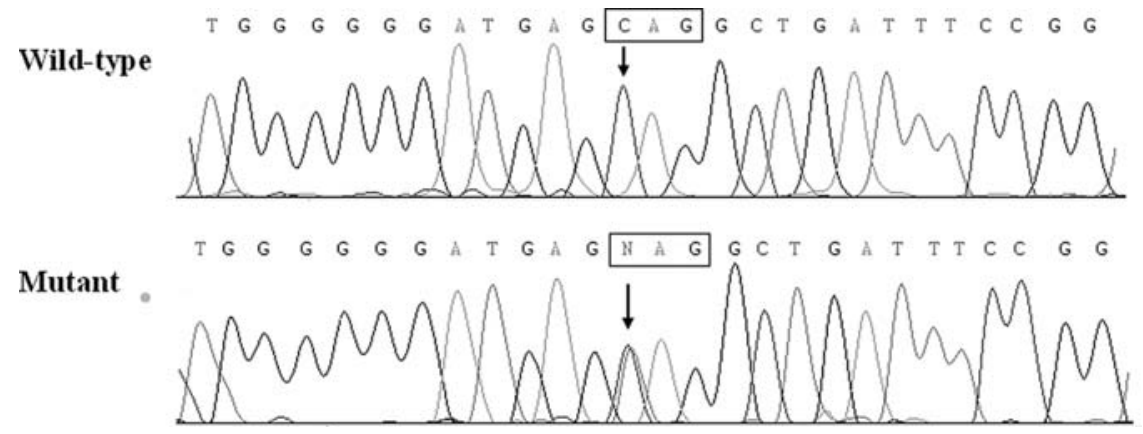

Figure 2. Sequence chromatograms around connexin 40 amino acid residue 49 in the control and proband. The arrow indicates the homozygous $\mathrm{C}$ nucleotide in the control (wild-type) or the heterozygous $\mathrm{C} / \mathrm{T}$ nucleotides in the proband (mutant). The square denotes the nucleotides comprising the forty-ninth codon of connexin40.

Statistical analysis. Data are expressed as the means \pm SD. Continuous variables were tested for normality of distribution and the Student's unpaired t-test was used for the comparison of the numeric variables between the patient and the control groups. The comparison of the categorical variables between the 2 groups was performed using Pearson's $\chi^{2}$ test or Fisher's exact test, when appropriate. A 2 -sided P-value of $<0.05$ was considered to indicate statistical significance.

\section{Results}

Characteristics of the study participants. A total of 126 unrelated kindreds with familial AF were recruited and clinically evaluated in contrast to a cohort of 200 ethnically matched unrelated healthy individuals as the controls. None of them had traditional risk factors for AF. There were no significant differences between the proband and the control groups in the baseline characteristics including age, gender, body mass index, blood pressure, fasting blood glucose, serum lipid levels, left atrial dimension, left ventricular ejection fraction, heart rate at rest, as well as lifestyle (data not shown). In this study, 6 probands were also diagnosed with hypertension in accordance to the criterion that the average systolic or diastolic blood pressure ( 2 readings made after 5 min rest in the sitting position) was $\geq 140$ or $\geq 90 \mathrm{~mm} \mathrm{Hg}$, respectively. However, at the time of the initial diagnosis of $\mathrm{AF}$, their blood pressures were normal. The clinical characteristics of the 126 probands with familial AF are shown in Table I.

Connexin40 mutation. The probands in 126 kindreds with familial AF were genetically evaluated. Direct sequencing of the coding region of the gene for the atrial-specific gap junction protein, connexin40, was performed after PCR amplification of genomic DNA from the 126 index patients. A heterozygous substitution of $\mathrm{T}$ for $\mathrm{C}$ in the first nucleotide of codon 49 , corresponding to a $\mathrm{C}$ to $\mathrm{T}$ transition at nucleotide position 145 from the translation initiation codon, was identified in 1 of the probands. The proband presented with paroxysmal AF (in combination with incomplete right bundle branch block) as frequently as once a week. A representative ECG of the proband with AF is recorded in Fig. 1. The detected variation in connexin40 is shown in Fig. 2. The c. $145 \mathrm{C}>\mathrm{T}$ mutation was predicted to introduce a premature stop codon at amino acid position 49 (p.Q49X). Connexin40 topologically consists of a cytoplasmic N-terminus, 4 membrane-spanning domains linked by 1 cytoplasmic and 2 


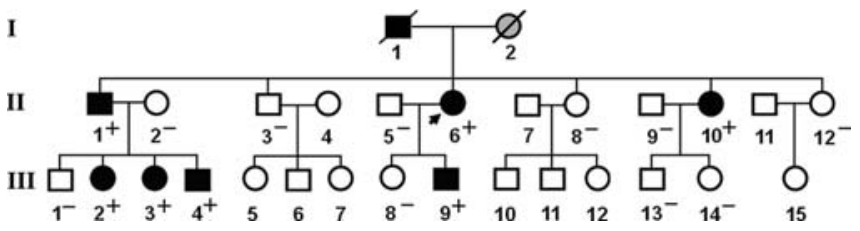

Figure 3. Pedigree structure of a family with atrial fibrillation. Family members are identified by generations and numbers; squares indicate male family members; circles, female members; symbols with a slash, the deceased members; closed symbols, affected members; open symbols, unaffected members; stippled symbols, members with phenotype undetermined; arrow, proband; (+), carriers of the heterozygous mutation; and (-), non-carriers.

extracellular loops, and a cytoplasmic C-terminus, and the truncated protein eliminates most of the functionally important domains leaving only the $\mathrm{N}$-terminus and the first transmembrane segment. This novel nonsense mutation was not present in the 200 unrelated control individuals. DNA from all the available relatives of the proband was subsequently sequenced for the presence of the p.Q49X mutation and the results displayed that the mutation was present in all 7 affected living family members, but was absent in the unaffected family members tested. The analysis of the pedigree demonstrated that the mutation co-segregated with AF transmitted as an autosomal dominant trait in the family with complete penetrance. The pedigree structure of the family is illustrated in Fig. 3. The phenotypic characteristics and results of the genetic screening of the pedigree members are listed in Table II.

\section{Discussion}

In the present study, we report a previously unrecognized nonsense mutation of connexin 40 identified in a family with familial AF. This novel heterozygous mutation, present in all the affected living family members and absent in the unaffected relatives tested and 200 unrelated control individuals, introduced a premature stop codon at amino acid 49 disrupting the connexin 40 , an $\alpha 5$ gap junction channel protein. The truncation deleted 3 transmembrane domains, 3 loop regions and the $\mathrm{C}$-terminus, preserving the $\mathrm{N}$-terminus and the first transmembrane segment. Therefore, it is highly likely that the p.Q49X mutation causes a loss of connexin40 function and that haploinsufficiency is the pathophysiological mechanism underlying the cardiac rhythm disturbance in the family.

In addition to the inability to generate full-length functional proteins, mRNAs harboring premature termination codons can be selectively degraded by a surveillance mechanism called nonsense-mediated mRNA decay (NMD), resulting in the decreased abundance of mutant mRNA transcripts rather than in the production of truncated dysfunctional proteins (38). Nonsense-containing mRNAs targeted by NMD can be generated by naturally occurring frameshift and nonsense mutations, splicing errors, leaky $40 \mathrm{~S}$ scanning, and the

Table II. Phenotypic characteristics and status of the connexin40 mutation in the pedigree members.

\begin{tabular}{|c|c|c|c|c|c|c|c|c|c|}
\hline \multicolumn{4}{|c|}{ Subject information } & \multirow{2}{*}{$\frac{\text { Phenotype }}{\mathrm{AF} \text { (Classification) }}$} & \multicolumn{2}{|c|}{ Electrocardiogram } & \multicolumn{2}{|c|}{ Echocardiogram } & \multirow{2}{*}{$\frac{\text { Genotype }}{\text { Q49X }}$} \\
\hline Identity & Gender & $\begin{array}{l}\text { Age at time of } \\
\text { study (years) }\end{array}$ & $\begin{array}{l}\text { Age at time of AF } \\
\text { diagnosis (years) }\end{array}$ & & $\begin{array}{l}\text { P-wave } \\
\text { (ms) }\end{array}$ & $\begin{array}{l}\text { QRS interval } \\
\quad(\mathrm{ms})\end{array}$ & $\begin{array}{l}\text { LAD } \\
(\mathrm{mm})\end{array}$ & $\begin{array}{l}\text { LVEF } \\
(\%)\end{array}$ & \\
\hline $\mathrm{I}-1$ & M & $63^{*}$ & 34 & Permanent & N/A & 94 & N/A & N/A & N/A \\
\hline II-1 & M & 71 & 39 & Permanent & N/A & 92 & 40 & 58 & + \\
\hline II-2 & $\mathrm{F}$ & 68 & N/A & N/A & 94 & 100 & 32 & 65 & - \\
\hline II-3 & M & 67 & N/A & N/A & 108 & 96 & 38 & 55 & - \\
\hline II-5 & M & 66 & N/A & N/A & 98 & 92 & 33 & 62 & - \\
\hline II-6 & $\mathrm{F}$ & 64 & 32 & Paroxysmal & 92 & 106 & 39 & 64 & + \\
\hline II-8 & $\mathrm{F}$ & 60 & N/A & N/A & 90 & 92 & 36 & 65 & - \\
\hline II-9 & M & 62 & N/A & N/A & 86 & 90 & 35 & 60 & - \\
\hline II-10 & $\mathrm{F}$ & 58 & 30 & Permanent & N/A & 98 & 39 & 65 & + \\
\hline II-12 & $\mathrm{F}$ & 52 & N/A & N/A & 86 & 90 & 36 & 58 & - \\
\hline III-1 & M & 47 & N/A & N/A & 102 & 86 & 34 & 62 & - \\
\hline III-2 & $\mathrm{F}$ & 45 & 41 & Paroxysmal & 98 & 92 & 32 & 58 & + \\
\hline III-3 & $\mathrm{F}$ & 41 & 32 & Permanent & N/A & 96 & 31 & 55 & + \\
\hline III-4 & M & 37 & 35 & Paroxysmal & 90 & 84 & 36 & 60 & + \\
\hline III-8 & $\mathrm{F}$ & 40 & N/A & N/A & 86 & 98 & 33 & 58 & - \\
\hline III-9 & M & 38 & 38 & Paroxysmal & 84 & 90 & 38 & 64 & + \\
\hline III-13 & M & 36 & N/A & N/A & 80 & 86 & 32 & 56 & - \\
\hline III-14 & $\mathrm{F}$ & 33 & N/A & N/A & 88 & 82 & 30 & 60 & - \\
\hline
\end{tabular}

$\mathrm{AF}$, atrial fibrillation; F, female; M, male; N/A, not available or not applicable; LAD, left atrial dimension; LVEF, left ventricular ejection fraction. (+) Indicates present and (-) denotes absence. ${ }^{*}$ Age at time of death. 
utilization of alternative AUG initiation sites (39). A major physiological role of the NMD pathway is to limit the synthesis of C-terminally truncated polypeptides, protecting the cell from its deleterious dominant-negative or gain-offunction effects (40). According to the '50-55 nt boundary rule', NMD is triggered when the premature translation termination codon locates $>50-55$ nucleotides upstream of the last exon-exon junction (41). However, if a nonsense mutation is sufficiently AUG-proximal, it does not follow the proposed rule and escapes from NMD (39). Hence, the p.Q49X mutation of connexin40 identified in this study, in patients with familial AF, possibly avoided NMD, yielding curtailed loss-of-function polypeptides.

Our results are supported by other studies on the connexin40 loss-of function mutations or polymorphisms predisposing to idiopathic AF by impairing or reducing gapjunction assembly. Similar to our findings, Gollob et al identified 4 novel heterozygous missense mutations of connexin40 in 4 of the 15 patients with lone AF, of which 3 mutations (p.G38D, p.P88S and p.M163V) were found in the cardiac-tissue specimens but not in the peripheral lymphocytes, and 1 mutation (p.A96S) was detected in both the cardiac tissue and lymphocytes. The p.A96S variant was absent in the patient's 3 siblings and spouse but was present in his 2 sons without a history of AF, and in 1 out of the 120 controls. Functional analysis of the mutant connexin 40 proteins revealed an impaired intracellular transport or reduced intercellular electrical coupling (23). By the sequencing of the 5' untranslated exon and the proximal promoter region of the connexin40 gene (GenBank accession no. AF246295) in patients with familial atrial standstill, Groenewegen et al found 2 closely linked polymorphisms, of which 1 was a G to A transition at 44 nucleotides upstream of the transcription start site $(-44 \mathrm{G}>\mathrm{A})$, and the other was a substitution of $\mathrm{G}$ for $A$ in exon 1 at 71 nucleotides downstream of the transcription start site $(+71 \mathrm{~A}>\mathrm{G})$. Luciferase reporter gene assays of the minor connexin40 haplotype $(-44 \mathrm{~A},+71 \mathrm{G})$ in connexin40expressing rat arterial smooth muscular cells showed a $>2$ fold decrease in promoter activity compared to the more common haplotype $(-44 \mathrm{G},+71 \mathrm{~A})$. The reduced connexin 40 expression could lead to a reduction in the total amount of connexin40 protein in vivo, providing an atrial electrophysiological substrate favoring arrhythmia susceptibility (33). Furthermore, the connexin 40 polymorphisms were strongly associated with the increased spatial dispersion of refractoriness as a marker for enhanced atrial vulnerability and carriers of the -44AA genotype had a significantly higher risk of AF compared to those carrying the -44GG genotype (34). In a larger case-control study, the rare haplotype frequency of connexin40 $(-44 \mathrm{~A},+71 \mathrm{G})$ was statistically higher in the AF than in the control group. Also, functional studies using luciferase as the reporter have demonstrated that connexin 40 $(-44 \mathrm{~A},+71 \mathrm{G})$ had a significantly lower promoter activity than connexin40 $(-44 \mathrm{G},+71 \mathrm{~A})$ in atrial myocytes from mice (35).

The association of reduced connexin40 with the increased predisposition to arrhythmias has been reported in animal models. The targeted gene deletion of connexin40 in mice produced multiple abnormalities including increased sinoatrial node recovery time, decreased conduction velocity of the atria, atrioventricular node and bundle branch, and impaired sinoatrial propagation with atrial ectopic pacemakers, which developed arrhythmogenic substrate liable to AF $(42,43)$. In a canine sterile pericarditis model, the gap junction conduction-enhancing anti-arrhythmic peptide, Gap-134, improved conduction and reduced AF (44). Similarly, in a canine model of AF due to myocardial ischemia, the administration of ZP123, a gap junction conductanceimproving modifier, prevented ischemia-induced slow conduction, thus lessening AF occurrence and reducing AF duration (45).

It is well known that AF is a complex arrhythmia involved in multiple possible mechanisms. Despite the presence of an inherited defect (a favorable substrate for AF), within the myocardial tissue of affected patients from birth, the onset of genetically based AF often requires a trigger for initiation, presumably by exacerbating the already anomalous cardiac cellular electrophysiology in the existence of mutant protein. One of the most common triggers is the enhanced vagal tone mediated by muscarinic receptors, causing the uneven shortening of refractoriness in the atria and, hence, electrophysiological heterogeneity (46). The stimulation of muscarinic receptors has been shown to impair the cell-cell coupling mediated by gap junctions (47). Together with the data mentioned above, this experimental study suggests a potential pathogenic link between the increased cardiac parasympathetic nerve activity, the impaired myocardial intercellular electrical coupling, and the occurrence of AF.

Notably, connexin40 is an important determinant of impulse propagation in the atria as well as the specialized conduction system, and the aberrant expression of connexin 40 is responsible for AF. However, functional changes in connexin40 alone could not be sufficient for the significantly prolonged P-wave duration, PQ interval, QRS duration, and QTc duration in the surface ECG, as was observed in a certain family, as well as in other patients (23,33-35). In addition, in connexin40 knockout mice, the full deficiency in connexin40 was associated with altered ECG parameters, but in contrast, the haploinsufficiency for connexin40 was not (42). These findings imply that other factors combined with reduced coupling contribute to AF.

In conclusion, the present study links a nonsense mutation in the connexin 40 protein to familial $\mathrm{AF}$ and provides novel insight into the molecular mechanisms implicated in arrhythmogenesis.

\section{Acknowledgements}

We are indebted to the participants for their dedication to the study. This study was supported in part by grants from the Natural Science Foundation of Shanghai, China (no. 10ZR1428000), the National Natural Science Foundation of China (no. 30570768), the National Basic Research Program of China (no. 2010CB912604) (all to Y.-Q.Y.), and from the National Natural Science Foundation of China (no. 30871083) to X.L.

\section{References}

1. Go AS, Hylek EM, Phillips KA, Chang Y, Henault LE, Selby JV and Singer DE: Prevalence of diagnosed atrial fibrillation in adults: national implications for rhythm management and stroke prevention: the AnTicoagulation and Risk Factors in Atrial Fibrillation (ATRIA) Study. JAMA 285: 2370-2375, 2001. 
2. Lloyd-Jones DM, Wang TJ, Leip EP, et al: Lifetime risk for development of atrial fibrillation: the Framingham Heart Study. Circulation 110: 1042-1046, 2004.

3. Wolf PA, Abbott RD and Kannel WB: Atrial fibrillation as an independent risk factor for stroke: the Framingham Study. Stroke 22: 983-988, 1991.

4. Nattel S: New ideas about atrial fibrillation 50 years on. Nature 415: 219-226, 2002

5. Fox CS, Parise H, D'Agostino RB Sr, et al: Parental atrial fibrillation as a risk factor for atrial fibrillation in offspring. JAMA 291: 2851-2855, 2004

6. Ellinor PT, Yoerger DM, Ruskin JN and MacRae CA: Familial aggregation in lone atrial fibrillation. Hum Genet 118: 179-184, 2005.

7. Arnar DO, Thorvaldsson S, Manolio TA, Thorgeirsson G, Kristjansson K, Hakonarson $\mathrm{H}$ and Stefansson K: Familia aggregation of atrial fibrillation in Iceland. Eur Heart J 27: 708$712,2006$.

8. Christophersen IE, Ravn LS, Budtz-Joergensen E, Skytthe A, Haunsoe S, Svendsen JH and Christensen K: Familial aggregation of atrial fibrillation: a study in Danish twins. Circ Arrhythm Electrophysiol 2: 378-383, 2009.

9. Tsai CT, Lai LP, Lin JL, et al: Renin-angiotensin system gene polymorphisms and atrial fibrillation. Circulation 109: 1640-1646, 2004 .

10. Gudbjartsson DF, Arnar DO, Helgadottir A, et al: Variants conferring risk of atrial fibrillation on chromosome $4 \mathrm{q} 25$. Nature 448: 353-357, 2007

11. Gudbjartsson DF, Holm H, Gretarsdottir S, et al: A sequence variant in ZFHX3 on $16 \mathrm{q} 22$ associates with atrial fibrillation and ischemic stroke. Nat Genet 41: 876-878, 2009.

12. Benjamin EJ, Rice KM, Arking DE, et al: Variants in ZFHX3 are associated with atrial fibrillation in individuals of European ancestry. Nat Genet 41: 879-881, 2009.

13. Ellinor PT, Lunetta KL, Glazer NL, et al: Common variants in KCNN3 are associated with lone atrial fibrillation. Nat Genet 42: 240-244, 2010

14. Brugada R, Tapscott T, Czernuszewicz GZ, et al: Identification of a genetic locus for familial atrial fibrillation. N Engl J Med 336: 905-911, 1997

15. Ellinor PT, Shin JT, Moore RK, Yoerger DM and MacRae CA: Locus for atrial fibrillation maps to chromosome 6q14-16. Circulation 107: 2880-2883, 2003.

16. Oberti C, Wang L, Li L, Dong J, Rao S, Du W and Wang Q Genome-wide linkage scan identifies a novel genetic locus on chromosome 5 p13 for neonatal atrial fibrillation associated with sudden death and variable cardiomyopathy. Circulation 110 : 3753-3759, 2004.

17. Chen YH, Xu SJ, Bendahhou S, et al: KCNQ1 gain-of-function mutation in familial atrial fibrillation. Science 299: 251-254, 2003.

18. Lai LP, Tsai CC, Su MJ, Lin JL, Chen YS, Tseng YZ and Huang SK: Atrial fibrillation is associated with accumulation of aging-related common type mitochondrial DNA deletion mutation in human atrial tissue. Chest 123: 539-544, 2003.

19. Yang Y, Xia M, Jin Q, et al: Identification of a KCNE2 gain-offunction mutation in patients with familial atrial fibrillation. Am J Hum Genet 75: 899-905, 2004.

20. Olson TM, Michels VV, Ballew JD, et al: Sodium channel mutations and susceptibility to heart failure and atrial fibrillation. JAMA 293: 447-454, 2005.

21. Hong K, Bjerregaard P, Gussak I and Brugada R: Short QT syndrome and atrial fibrillation caused by mutation in $\mathrm{KCNH} 2$. J Cardiovasc Electrophysiol 16: 394-396, 2005

22. Olson TM, Alekseev AE, Liu XK, et al: Kv1.5 channelopathy due to KCNA5 loss-of-function mutation causes human atrial fibrillation. Hum Mol Genet 15: 2185-2191, 2006.

23. Gollob MH, Jones DL, Krahn AD, et al: Somatic mutations in the connexin 40 gene (GJA5) in atrial fibrillation. N Engl J Med 354: 2677-2688, 2006

24. Zhang X, Chen S, Yoo S, et al: Mutation in nuclear pore component NUP155 leads to atrial fibrillation and early sudden cardiac death. Cell 135: 1017-1027, 2008

25. Hodgson-Zingman DM, Karst ML, Zingman LV, et al: Atrial natriuretic peptide frameshift mutation in familial atrial fibrillation. N Engl J Med 359: 158-165, 2008.

26. Watanabe H, Darbar D, Kaiser DW, et al: Mutations in sodium channel beta1 - and beta2-subunits associated with atrial fibrillation. Circ Arrhythm Electrophysiol 2: 268-275, 2009.
27. Darbar D, Herron KJ, Ballew JD, et al: Familial atrial fibrillation is a genetically heterogeneous disorder. J Am Coll Cardiol 41: 2185-2192, 2003.

28. Jansen JA, van Veen TA, de Bakker JM and van Rijen HV: Cardiac connexins and impulse propagation. J Mol Cell Cardiol 48: 76-82, 2010 .

29. Vozzi C, Dupont E, Coppen SR, Yeh HI and Severs NJ: Chamber-related differences in connexin expression in the human heart. J Mol Cell Cardiol 31: 991-1003, 1999.

30. Hagendorff A, Schumacher B, Kirchhoff S, Lüderitz B and Willecke $\mathrm{K}$ : Conduction disturbances and increased atrial vulnerability in Connexin40-deficient mice analyzed by transesophageal stimulation. Circulation 99: 1508-1515, 1999.

31. Van der Velden HM, Ausma J, Rook MB, Hellemons AJ, van Veen TA, Allessie MA and Jongsma HJ: Gap junctional remodeling in relation to stabilization of atrial fibrillation in the goat. Cardiovasc Res 46: 476-486, 2000.

32. Severs NJ, Coppen SR, Dupont E, Yeh HI, Ko YS and Matsushita T: Gap junction alterations in human cardiac disease. Cardiovasc Res 62: 368-377, 2004.

33. Groenewegen WA, Firouzi M, Bezzina CR, et al: A cardiac sodium channel mutation cosegregates with a rare connexin40 genotype in familial atrial standstill. Circ Res 92: 14-22, 2003.

34. Firouzi M, Ramanna H, Kok B, et al: Association of human connexin40 gene polymorphisms with atrial vulnerability as a risk factor for idiopathic atrial fibrillation. Circ Res 95: e29-e33, 2004.

35. Juang JM, Chern YR, Tsai CT, et al: The association of human connexin 40 genetic polymorphisms with atrial fibrillation. Int $\mathrm{J}$ Cardiol 116: 107-112, 2007

36. Darbar D, Hardy A, Haines JL and Roden DM: Prolonged signal-averaged $\mathrm{P}$-wave duration as an intermediate phenotype for familial atrial fibrillation. J Am Coll Cardiol 51: 1083-1089, 2008.

37. Fuster V, Rydén LE, Cannom DS, et al: ACC/AHA/ESC 2006 Guidelines for the Management of Patients with Atrial Fibrillation: a report of the American College of Cardiology/ American Heart Association Task Force on Practice Guidelines and the European Society of Cardiology Committee for Practice Guidelines. Circulation 114: e257-e354, 2006.

38. Hentze MW and Kulozik AE: A perfect message: RNA surveillance and nonsense-mediated decay. Cell 96: 307-310, 1999.

39. Inácio A, Silva AL, Pinto J, et al: Nonsense mutations in close proximity to the initiation codon fail to trigger full nonsensemediated mRNA decay. J Biol Chem 279: 32170-32180, 2004.

40. Holbrook JA, Neu-Yilik G, Hentze MW and Kulozik AE: Nonsense-mediated decay approaches the clinic. Nat Genet 36: 801-808, 2004.

41. Maquat LE: Nonsense-mediated mRNA decay: splicing, translation and mRNP dynamics. Nat Rev Mol Cell Biol 5: 89-99, 2004.

42. Chaldoupi SM, Loh P, Hauer RN, de Bakker JM and van Rijen $\mathrm{HV}$ : The role of connexin40 in atrial fibrillation. Cardiovasc Res 84: 15-23, 2009.

43. Bagwe S, Berenfeld O, Vaidya D, Morley GE and Jalife J: Altered right atrial excitation and propagation in connexin 40 knockout mice. Circulation 112: 2245-2253, 2005.

44. Rossman EI, Liu K and Morgan GA: The gap junction modifier, GAP-134, improves conduction and reduces atrial fibrillation/ flutter in the canine sterile pericarditis model. J Pharmacol Exp Ther 329: 1127-1133, 2009.

45. Shiroshita-Takeshita A, Sakabe M, Haugan K, Hennan JK and Nattel S: Model-dependent effects of the gap junction conduction-enhancing antiarrhythmic peptide rotigaptide (ZP123) on experimental atrial fibrillation in dogs. Circulation 115: 310-318, 2007

46. Zipes DP, Mihalick MJ and Robbins GT: Robbins, Effects of selective vagal stellate ganglion stimulation on atrial refractoriness. Cardiovasc Res 8: 647-655, 1974.

47. Fritz S, Kunz L, Dimitrijevic N, Grunert R, Heiss C and Mayerhofer A: Muscarinic receptors in human luteinized granulosa cells: activation blocks gap junctions and induces the transcription factor early growth response factor-1. J Clin Endocrinol Metab 87: 1362-1367, 2002. 